around the reactor, and a metal chimney stack, more then $200 \mathrm{ft}$. high, towers over the metal shell. The reactor is intended primarily for research purposes and its scope of activities is very similar to that of the Pluto-type reactors, to which it bears some resemblance. The Ispra centre will provide a valuable addition to the Italian nuclear scene, which includes the centre for fundamental research at Frascati and the new centre for research studies to be built near Rome. Italy, in common with most countries in western Europe, is increasing its consumption of power at the rate of about 7 per cent a year, and with the hydroelectric power potential in the north fully exploited, Italy has begun a nuclear power programme that should give a capacity of $500 \mathrm{MW}$. by 1964. At present the 200-MW. reactor being built by the Nuclear Power Plant Company for Agip Nucleare is the most advanced of the reactors under construction.

\section{Braille Translation by Computer}

IBM Mathematicrans, working with the American Printing House for the Blind, have developed a process for translating printed text into Braille by computer. The computer used is an IBM 704 which can convert a 300-page book into Braille in an hour-a job that would take skilled translators more than six days. This new technique will make available many school and technical books now rarely produced in Braille, thus enlarging the possibilities for careers for the blind. To speed this translation, printed texts will be recorded on magnetic tape and distributed to IBM computer installations, where they will be translated and the cost borne by IBM United Kingdom, Ltd.

Writing Braille requires knowledge of many complicated rules, the symbols often changing their meaning in a different context. Braille consists of 63 combinations of six raised dots which represent not only the letters of the alphabet, numerals and punctuation marks, but also 183 special contractions and abbreviations, as in the case of shorthand. Texts to be translated by the computer are first transeribed on to punched cards. The cards are then fed directly into the computer, which has had previously stored in its memory a programme for conversion of English into Braille. The translated text emerges from the computer in coded symbols on punched cards, and these, in turn, are fed to the printer unit of the $I B M$ 704, which reproduces Braille symbols above the English text. After editing, the corrected punched cards are fed into an embossing machine which produces metal plates ready for use on a rotary press.

\section{Denudation and Burial of Archæological Structures}

THE British Association (Section $H$ ) has formed a special committee to "investigate by experiment the denudation and burial of archæological structures". The aim of the committee, the members of which are Dr. G. W. Dimbleby (chairman), Dr. P. Jewell (secretary), Prof. R. J. C. Atkinson, Dr. I. W. Cornwall and Dr. B. Proudfoot, is to obtain precise measurements of the rates at which soil moves and accumulates, how far buried objects may move in the soil, and the way in which buried objects disintegrate and decay. Building a simple ditch and bank with incorporated markers, and following the rate of silting of the ditch, and of denudation and spreading of the bank, formation of turf and compaction of soil, over the following years would help to answer some of the questions. Comparative results will be obtained from sites established in different parts of Britain. The observations should not only aid in the interpretation of archrological excavations but may throw more light on the changes that past land-use has produced. Buried materials will include wood, charcoal, bone and metal, treated in different ways, and their examination in the future may enable more information to be obtained from the accumulating finds from archæological sites. The committee will be very glad to hear from anyone interested in the project, particularly those whose specialist knowledge might help in laying out the structures, and who in turn might derive in. formation of interest from the experiments. The secretary of the committee is Dr. P. A. Jewell, Royal Veterinary College, London, N.W.1.

\section{A Century of Biological Research in Illinois}

The Illinois Natural History Survey Bulletin (27; 1958), entitled "A Century of Biological Research" (Pp. vi +85-234. Urbana : Illinois Natural History Survey, 1958), deals with the development of biological research in a mainly agricultural community, in which the practical problems affecting land-use and agrioulture have largely controlled the outlook of the investigators as well as the policy controlling development. This is reflected in the five main lines of progress summarized, namely, economic entomology, faunistic surveys, applied botany and plant pathology, aquatic biology, and wild-life conservation. The work has, however, included notable contributions of a fundamental nature, and the brief outlines of these included in this Bulletin are of considerable interest. The rapid changes in Illinois due to the transformation of woodland and swamp to farmland, and to the utilization of the now 'vanishing prairies', have all greatly affected the plant and animal populations. These have been followed in studies and records which can scarcely be paralleled anywhere over so long a period. As one example, map records are given of the density of populations of a wheat predator, the chinch bug (Blissus leucopteris), available since 1840. Other examples trace the gradual disappearance of prairie animals, such as the prairie chicken, as arable land has replaced grassland, while the recorded fluctuations of the bob-white quail or of ducks and geese or of introduced pheasants, in areas of diverse ecological character, have abundantly justified the bird-census techniques which were adopted at an early date. Very well known to freshwater biologists are the massive pioneer papers on the plankton, bottom-fauna and fishes of the Illinois River. Not only do they record some of the earliest quantitative work in these fields but also the 'indicator' species present and succeeding one another, as drainage and pollution modified the character of the river. This Bulletin is therefore a valuable guide to records which trace the growth of modern aspects of wild-life conservation from earlier efforts concerned simply with crop protection. It is, incidentally, also a memorial to the genius and foresight of A. S. Forbes, who for so long guided the destinies of the organization.

\section{National Science Foundation Fellowships}

THE National Science Foundation has awarded 1,100 graduate fellowships in the natural sciences and allied fields for the academic year 1959-1960. In addition, the Foundation has announced the names of 160 winners of regular postdoctoral fellowships. Of 